\title{
Training South African clinician-scientists: Lessons from the University of Cape Town's intercalated programme
}

\author{
R J Burman, ${ }^{1} \mathrm{MB}$ ChB, BMedSci Hons, MSc (Med); T J de Wet, ${ }^{2}$ BMedSci Hons; M Amoni, ${ }^{3}$ MB ChB, BMedSci Hons, MSc (Med); \\ K M Düsterwald, ${ }^{4} \mathrm{MB}$ ChB, BMedSci Hons, MSc (Med); D M Favara, ${ }^{5} \mathrm{MB}$ ChB, MSc, DPhil, MRCP; \\ M Setshedi, ${ }^{6}$ MB ChB, FCP (SA), MPH, Cert Gastroenterology (SA), PhD; C L Rametse, ${ }^{7}$ MB ChB, BMedSci Hons; A A Katz, ${ }^{8} \mathrm{PhD}$ \\ ${ }^{1}$ Nuffield Department of Clinical Neurosciences, University of Oxford, UK \\ ${ }^{2}$ MRC/NHLS/UCT Molecular Mycobacteriology Research Unit, Division of Medical Microbiology, Department of Pathology and \\ Institute of Infectious Disease and Molecular Medicine, Faculty of Health Sciences, University of Cape Town, South Africa \\ ${ }^{3}$ Department of Cardiology, Katholieke Universiteit Leuven, Belgium \\ ${ }^{4}$ Port Elizabeth Hospital Complex, Port Elizabeth, South Africa \\ ${ }^{5}$ Department of Medical Oncology, The Royal Marsden Hospital, London, UK \\ ${ }^{6}$ Division of Gastroenterology, Department of Medicine, Faculty of Health Sciences, Groote Schuur Hospital and University of Cape Town, South Africa \\ ${ }^{7}$ Division of Immunology, Department of Pathology and Institute of Infectious Disease and Molecular Medicine, Faculty of Health Sciences, \\ University of Cape Town, South Africa \\ ${ }^{8}$ Department of Integrative Biomedical Sciences and Institute of Infectious Disease and Molecular Medicine, Faculty of Health Sciences, \\ University of Cape Town, South Africa
}

Corresponding author: A A Katz (arieh.katz@uct.ac.za)

\begin{abstract}
In 2011, the Faculty of Health Sciences at the University of Cape Town, South Africa (SA), established the Clinician-Scientist Training Programme (UCTCSTP), consisting of intercalated BMedSci Hons/MB ChB and integrated MB ChB/MSc/PhD tracks. We report and reflect on the programme's performance and challenges. The UCTCSTP has so far enrolled 71 students: 51 have received BMedSci Hons degrees and 4 have received Master's degrees, while there are 14 BMedSci Hons, $4 \mathrm{MSc}$ and $4 \mathrm{PhD}$ candidates. Graduates have produced significant research outputs, and many remain actively engaged in research. The UCTCSTP has been successful in encouraging a cohort of future clinician-scientists, but should aim to broaden and improve its appeal to address the need to transform and grow the SA clinical academic workforce. As graduates progress with their postgraduate clinical training, they require institutional support and guidance, which may necessitate policy reform.
\end{abstract}

S Afr Med J 2019;109(12):914-918. https://doi.org/10.7196/SAMJ.2019.v109i12.14175

Clinician-scientists - individuals with training in both clinical medicine and scientific methods - have been significant contributors to the global scientific output, illustrated by the importance of clinical research to national research production. ${ }^{[1]}$ South Africa (SA)'s unique clinical burden and patient population have produced worldleading experts in local diseases, and inspired clinical, translational and fundamental research.

Unfortunately, underfunding and an ageing medical academic workforce place this expertise and research output at risk, as highlighted in the 2009 Academy of Science of SA (ASSAf) report on revitalising clinical research in SA. ${ }^{[2]}$ In response, an early national framework to train clinician-scientists was developed with the ambitious mandate of producing $1000 \mathrm{PhD}$ degrees in medical science over 10 years. ${ }^{[3]}$

While medical training is well defined, research training is more flexible and can take the form of research degrees, including a BMedSci Hons, MSc and PhD. An efficient route to training clinicianscientists is by integrating research training into undergraduate medical training. However, this requires an extended period of study and bears a significant cost to the individual in terms of time, potential fees and lost earnings. Combined degrees and intercalated programmes, often accompanied by full funding, aim to mitigate this cost. In resource-rich countries, these programmes are well established, ${ }^{[4,5]}$ but in countries where such programmes are not available, aspiring clinician-scientists are often required to plan their own training and personally take on much of the cost.

The University of Cape Town was the first university in Africa to establish a Clinician-Scientist Training Programme (UCTCSTP) that aimed to introduce optional research training in the undergraduate medical curriculum. ${ }^{[6]}$ The UCTCSTP offers academically highperforming students an extra course in molecular medicine during the third year of the MB ChB degree. The molecular medicine course is required for $\mathrm{MB} \mathrm{ChB}$ students to meet the Higher Education Qualification Sub-Framework (HEQS-F) level and prescribed credit for admission to the BMedSci Hons programme, which they undertake as a 'year out' from the $\mathrm{MB} \mathrm{ChB}$ programme between years 3 and 4 . After completing the Honours year, students have the opportunity to extend postgraduate scientific training in the form of either an MSc or a PhD degree, completed before, after or concurrently with years $4-6$ of undergraduate medical training (Fig. 1A).

The UCTCSTP has run successfully for 8 years and is the largest of its kind nationally, representing a model for training a 


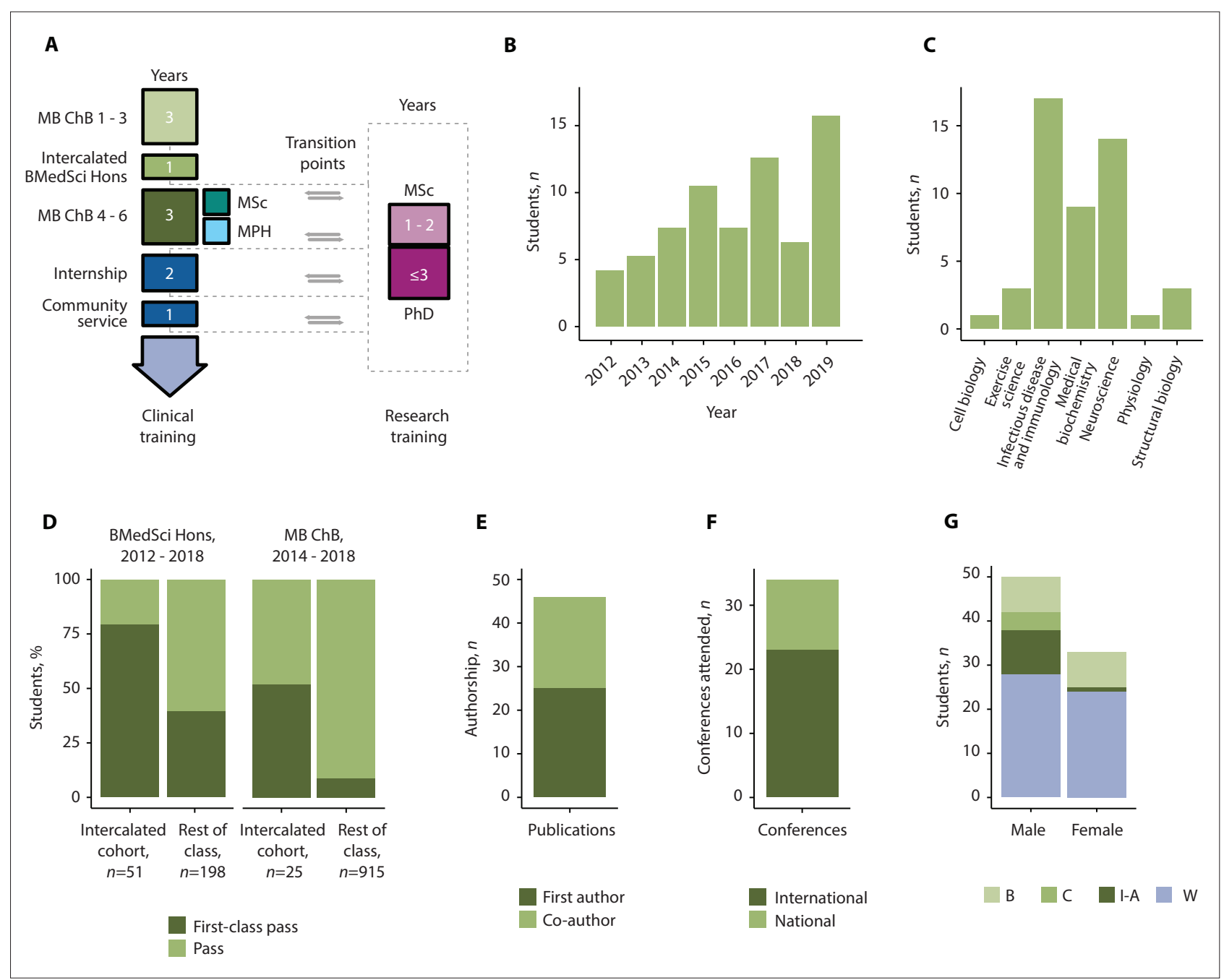

Fig. 1. Progress of the UCT Clinician-Scientist Training Programme (UCTCSTP). (A) The UCTCSTP allows students to combine clinical and research training at different stages of their undergraduate medical training. Students are able to transition in and out of the $M B C h B$ curriculum to pursue additional research degrees. (B) The first intercalated BMedSci Hons class undertook the Honours degree in 2012 - there has been a general increase in class size over time. (C) Students have enrolled into a wide range of BMedSci Hons streams, but have clear subject choice preferences. (D) Overall, UCTCSTP graduates achieved higher rates of first-class passes for their BMedSci Hons compared with the rest of the Honours graduates and $M B$ ChB degrees compared with the remainder of the graduating cohort. (E) UCTCSTP graduates have published research papers. (F) UCTCSTP graduates have participated in scientific conferences. (G) Overall, more males than females have enrolled in the UCTCSTP, and white students have comprised the majority of the cohort. ( $B=$ black African; $C=$ coloured $;-A=$ Indian-Asian; $W=$ white. $)$

clinical academic workforce. Similar programmes have recently been launched at the University of the Witwatersrand and are at a planning stage at the universities of Pretoria and KwaZulu-Natal. Five years after its initial description in the $S A M J,{ }^{[6]}$ we provide an updated assessment of the successes and challenges of the UCTCSTP. We highlight the need for increased funding and policy reform to aid the development of a clinical academic workforce in SA.

\section{Successes and concerins of the UCTCSTP cohort (2011 - 2019)}

Since 2011, 71 MB ChB students have enrolled in the UCTCSTP and completed the molecular medicine course in their third year of $\mathrm{MB} \mathrm{ChB}$ studies. Class sizes have generally increased with time (Fig. 1B), reflecting a growing awareness among the preclinical medical students of the UCTCSTP and its value. In 2019, there were more suitable applicants for the molecular medicine course than capacity allowed. Sixty-five of the graduating molecular medicine students have subsequently enrolled in the intercalated BMedSci Hons degree.

Although the Honours-stream choices vary across cohorts, the infectious disease and immunology and neuroscience streams have been the most popular (Fig. 1C). This reflects the research strengths of UCT's Institute of Infectious Disease and Molecular Medicine and the recently established UCT Neuroscience Institute.

Fifty-one BMedSci Hons degrees have been completed and the remaining 14 are in progress. The majority of UCTCSTP students returned to the fourth year of the $\mathrm{MB} \mathrm{ChB}$ programme on completion of their Honours year, although 1 student opted to leave the MB $\mathrm{ChB}$ programme entirely and embarked on MSc and $\mathrm{PhD}$ studies after completing the Honours degree. Twenty-five students subsequently graduated with $\mathrm{MB} \mathrm{ChB}$ degrees and are at various stages of postgraduate training - primarily internship - although exceptions are described below.

In general, UCTCSTP students have performed well academically in both the BMedSci Hons and MB ChB degrees (Fig. 1D). Overall, 
higher rates of first-class passes are seen in the UCTCSTP cohort than in the remainder of the Honours class. For the BMedSci Hons degree, $80 \%(n=41)$ of the 51 students $(2012-2018)$ achieved a firstclass pass compared with $40 \%(n=80)$ of the remainder of the class $(n=198)$ in the same period. Similarly, for MB ChB, 52\% $(n=13)$ of the 25 UCTCSTP MB ChB graduates between 2014 and 2018 achieved a first-class pass compared with $9 \%(n=81)$ of the remainder of the MB ChB graduates $(n=915)$ during the same period. While this may be an indication of the stringent selection criteria of the UCTCSTP, it is nonetheless suggestive of sustained academic achievement among the UCTCSTP cohort.

Moreover, the UCTCSTP proved to be productive in generating immediate research output. This is reflected in the number of publications and conference presentations by graduates of the programme - 45 publications, including 25 (56\%) first-author publications (Fig. 1E). Furthermore, graduates have presented at 34 conferences, two-thirds of them international (Fig. 1F). It is worth reiterating that this research output was achieved while most of the students were still pursuing their undergraduate medical training.

On average, so far, the UCTCSTP cohort has consisted of a higher number of males than females (Fig. 1G). Students of colour have represented $37 \%$ of the cohort, although they comprise the majority of the UCT MB ChB class. This is a concern, and worth highlighting in view of the other intercalated programmes being established nationally. There are a number of possible reasons for this pattern. Entry requirements to the UCTCSTP are based on course marks $\sim 10 \%$ of the MB ChB class qualify; of these, fewer than half are black students. However, of the black students who do qualify, the majority do not opt to join the UCTCSTP. Among qualifying candidates, there are concerns about the financial effects of delaying a medical qualification. Repaying student loans, family dependence on future earnings and inflexible bursary schemes create significant deterrents. Moreover, limited mentoring and support may hinder interest in this programme. If provided, mentoring could cultivate, nurture and assist potential students with navigating these issues. It is worth noting that these perceived barriers are based on personal accounts. A systematic exploration of the barriers should be examined to strengthen evidence for future reports. Interestingly, many of the perceived barriers have also recently been documented as reasons for the declining clinician-scientist workforce in the USA. ${ }^{[7]}$

To partially alleviate these hurdles, a key pillar of the UCTCSTP was to fund the cost of tuition and living expenses during the intercalated Honours degree and for those pursuing MSc and $\mathrm{PhD}$ degrees. This was initially enabled by contributions from Boehringer Ingelheim, the UCT Clinical Scholar Programme and the Ada and Bertie Levenstein Trust. Since 2016, the programme has been funded by the SA Medical Research Council (MRC), which established a National Medical Scientists Training Programme to fund clinicianscientist training programmes for medical students at SA universities.

Currently, funding does not cover fees on return to years $4-6$ of the MB ChB degree. This may inadvertently exclude students who are not well-off (or those with families dependant on expeditious earnings), and has been a dominant source of concern for suitable and interested black students who did not undertake the UCTCSTP. Moreover, graduating with a BMedSci Hons disqualifies intercalated students from the National Student Financial Aid Scheme (NSFAS) on return to years 4 - 6 of the MB ChB degree, as NSFAS funding is only applicable to students who do not have a postgraduate degree. Negotiating with funders is necessary to alleviate this barrier, considering the calls to, and necessity of, transforming SA's academic workforce. ${ }^{[8,9]}$ Funding issues are also compounded if students wish to continue with an intercalated MSc or PhD. Funding for the entire programme, akin to the National Institutes of Health (NIH)-funded $\mathrm{MD} / \mathrm{PhD}$ programmes in the USA, may need to be considered if the cohort is to increase in size and ethnic diversity.

\section{Postgraduate training after the intercalated Honours year}

The intention of the UCTCSTP was to offer a 1-year introduction to basic science research through the BMedSci Hons degree and to feed a few students into MSc and PhD programmes, either immediately after Honours or after the completion of their MB ChB studies. This flexibility was important, as each path has advantages and drawbacks, and flexibility in training allows individuals to mitigate the costs as they see fit.

Eight Honours graduates have enrolled in Master's programmes. Five have enrolled in concurrent Master's degrees alongside the final years of the $\mathrm{MB} \mathrm{ChB}$ programme (MB $\mathrm{ChB} / \mathrm{MSc}$ ), which generally build on the work completed during the Honours course. One student opted to pursue a Master's degree in public health concurrently with her MB $\mathrm{ChB}$ studies (MB ChB/MPH). Four of the 6 students have already graduated with their MSc/MPH and MB ChB degrees, and 2 students are on track to graduate. The remaining 2 of the 8 Honours graduates are enrolled in full-time MSc programmes 1 after the Honours year, prior to returning to $\mathrm{MB} \mathrm{ChB}$, and the other after internship, prior to community service.

Four students have enrolled in $\mathrm{PhD}$ programmes. One student who enrolled in an MSc after Honours upgraded to $\mathrm{PhD}$, and is on track to complete the $\mathrm{PhD}$ this year and return to the $\mathrm{MB} \mathrm{ChB}$ programme next year. Another student enrolled in a PhD programme after internship, with the experience of clinical practice influencing her research questions. Finally, 2 of the abovementioned $\mathrm{MB} \mathrm{ChB} / \mathrm{MSc}$ graduates are enrolled in fully-funded $\mathrm{PhD}$ programmes abroad.

It is encouraging to note the number of UCTCSTP graduates engaged in further training, particularly $\mathrm{PhD}$ studies. Unfortunately, the route is not without difficulties. Even though $\mathrm{PhD}$ studies have been funded through a variety of fellowships, they add years to a training regimen that already includes 2 internship years and 1 community-service year. This comes with a significant delay in earning a full clinical salary and is a major deterrent for candidates from previously disadvantaged backgrounds, who are essential personnel for the transformation of the clinical academic landscape.

Undertaking a $\mathrm{PhD}$ degree immediately after $\mathrm{MB} \mathrm{ChB}$ studies and deferring internship, is a favourable option; 2 of the UCT MB ChB/ $\mathrm{MSc}$ graduates are enrolled in fully-funded $\mathrm{PhD}$ programmes abroad. Health Professions Council of SA (HPCSA) rules stipulate that medical graduates can defer their internship by only 1 year. Fortunately, there are mechanisms that allow for deferment of the internship for $\mathrm{PhD}$ or other postgraduate studies. However, the individual candidate would need to apply to the HPCSA and motivate for the deferment. We can only hope that the HPCSA will be forthcoming in approving requests for deferral, as these young $\mathrm{MB} \mathrm{ChB}$ graduates wish to become clinician-scientists in SA and not abroad.

Community service was introduced to improve national health services. The National Department of Health is being petitioned by convenors of the UCTCSTP to recognise $\mathrm{PhD}$ studies completed during, or immediately after, medical studies as being equivalent to community service. This will mitigate the cost of a $\mathrm{PhD}-$ in time and money - and make the route to become a clinicianscientist less arduous. It may also motivate more students, especially from previously disadvantaged backgrounds, to consider training as clinician-scientists and become academic clinicians. 


\section{Developing careers as South African clinician-scientists}

The UCTCSTP integrates biochemical and molecular research training into undergraduate medical training and provides graduates with laboratory skills and experience. Furthermore, in contrast to many academic clinicians in SA, who to a large extent undertake $\mathrm{PhD}$ research projects that are clinically focused, UCTCSTP students undertake laboratory-based research projects that prepare them to become clinician-scientists who can engage in fundamental scientific research. Nurturing and inspiring students at undergraduate level through early exposure is critical to shaping their interest in fundamental research as part of their career. At UCT, student societies and mentoring schemes have been instrumental in cultivating interest in and a passion for the clinical surgical discipline. ${ }^{[10]}$ Introducing such initiatives for clinician-scientists could provide a platform to inform students of opportunities in research and receiving mentorship from established clinician-scientists.

Currently, the long-term impact of the programme on the academic healthcare workforce cannot be assessed. Most graduates from the first cohort (2011) have only just finished community service and are starting their postgraduate careers. Long-term success will be partially dependent on further support as trainees progress. For graduates hoping to develop careers as clinician-scientists, the most significant challenge may be the establishment of a research career within the constraints of SA medical practice and specialisation.

For students engaged in their internship or community-service years, it is difficult to maintain research interests while operating in a resource-constrained public healthcare system with a large disease burden. Junior doctors face many hours of overtime work, a relative lottery for facility placement that may remove them from academic medical centres, and internship or communityservice programmes without dedicated time for research. This is in contrast to academically focused internships (in the UK) or residencies (in the USA) that enable simultaneous development of clinical skills and a research career. ${ }^{[11]}$ Similar barriers exist during and after specialisation, when clinical responsibilities may restrict opportunities for laboratory-based research and minimise dedicated research time. The limited availability of posts at academic hospitals is an additional concern, as is the availability of funds necessary to establish independent research programmes.

These issues require continued attention at a policy and institutional level. Previous proposals included establishing a clinical academic career track, ${ }^{[2]}$ which would be further buffered by considerations for academic career development in internship placement, specialisation and early career development. ${ }^{[12]}$

\section{Conclusions}

Fundamentally, clinician-scientists sit at an interface of basic and clinical science, which uniquely positions them to identify research problems, develop realistic solutions and lead multidisciplinary teams that aim to improve health by furthering knowledge. These are vital skills that contribute to the clinical research and service capacity of SA. The UCTCSTP offers a national model for training clinicianscientists. It has been largely successful, but faces challenges, including diversifying the cohort and continued professional development of its graduates. Sustained and increased financial support, concessions for community service and academic-focused clinical training may assist the programme in its aims. The ultimate success of its graduates depends on continued development and support.

\section{Acknowledging a founder: Prof. Bongani Mayosi (1967 - 2018)}

In reflecting on the UCTCSTP, we acknowledge the late Prof. Bongani Mayosi, a cofounder of this programme. Prof. Mayosi was involved in the early establishment of the UCTCSTP and often referred to it as our baby. He was a strong and instrumental advocate for clinician-scientists in SA and spurred change at national and institutional levels. ${ }^{[1-3]}$ His efforts were key to driving the commitments of the National Department of Health and the SAMRC in prioritising the training of clinicianscientists. He viewed fundamental research as key to enabling our health system to produce and use knowledge in a self-sustaining feedback loop, with problems identified at African clinics, solved at the laboratory bench, and then implemented at the same clinics. ${ }^{[1]}$

Prof. Mayosi epitomised excellence in blending outstanding clinical practice with world-class research. His unique passion for research was evident in his completion of a BMedSci degree concurrent with his medical studies at the University of KwaZulu-Natal. During this self-conceived intercalated programme, he conducted research on the anatomy of the navicular bone. While a far cry from his later impact regarding tuberculosis pericarditis, rheumatic heart disease and cardiomyopathy, it demonstrates how an early introduction to research could spark a curiosity that later led to the development of an internationally acclaimed clinician-scientist.

His infectious optimism and passion for SA problems ignited research ambitions in many aspiring and established healthcare professionals. He is fondly remembered for emphasising that scientific advancement is only accomplished by those tenacious enough to persevere through unchartered territories.

We owe an invaluable debt of gratitude to Prof. Mayosi. Kuwe, umbonisi wethu owandulela phambili ohambe, eli phupha osiphathise lona, siya kuzama ukufezekisa (To you, our departed, visionary forerunner, this dream you have entrusted to us, we endeavour to realise).

\section{Declaration. None.}

Acknowledgements. The authors would like to thank all who have supported the development of the UCTCSTP, including the funders. Author contributions. RJB, TJdW, MA, KMD, AAK: contributed equally to the inception, planning, writing and editing of the manuscript; DMF, MS, CLR: assisted in the writing and editing of the manuscript.

Funding. UCT's Vice Chancellor Strategic Fund, the SAMRC, Boehringer Ingelheim and the Ada and Bertie Levenstein Trust. This article was made possible through partial funding support by the SAMRC through its Division of Research Capacity Development under the National Medical Scientists Training Programme from funding received from the SA National Treasury. The content is the sole responsibility of the authors and does not necessarily represent the official views of the SAMRC or the funders.

\section{Conflicts of interest. None.}

1. Senkubuge F, Mayosi BM. The state of the National Health Research system in South Africa: Leadership and governance. South African Health Review. 2012. https://repository.up.ac.za/bitstream/ handle/2263/21499/Senkubuge_State\%282012\%29.pdf? sequence=18isAllowed=y (accessed 18 October 2019)

2. Mayosi BM, Dhai A, Folb P, et al. Consensus Report on Revitalising Clinical Research: A Study on Clinical Research and Related Training. Pretoria: Academy of Science of South Africa, 2009. https:// www.assaf.org.za/files/2009/09/ASSAf-Clinical-Report-2009.pdf (accessed 19 October 2019).

3. Mayosi B, Mekwa J, Blackburn J, et al. Strengthening Research for Health, Innovation and Development in South Africa: Proceedings and Recommendations of the 2011 National Health Research summit. Pretoria: Department of Health, 2012. https://www.ul.ac.za/application/downloads/National_Health_ Research_Summit_Report-2011.pdf (accessed 23 October 2019).

4. Hading CV, Akabas MH, Andersen OS. History and outcomes of 50 years of physician-scientist training in medical scientist training programs. Acad Med 2017;92(10):1390-1398. https://doi. org/10.1097/ACM.0000000000001779 
5. Barnett-Vanes A, Ho G, Cox TM. Clinician-scientist $\mathrm{MB} / \mathrm{PhD}$ training in the UK: A nationwide survey of medical school policy. BMJ Open 2015;5(12):e009852. https://doi.org/10.1136/bmjopen-2015-009852 6. Katz AA, Futter M, Mayosi BM. The intercalated BSc (Med) Honours/MB ChB and integrated MB ChB/ PhD tracks at the University of Cape Town: Models for a national medical student research training programme. S Afr Med J 2014;104(2):111-113. https:// doi.org/10.7196/samj.7639

7. Jain MK, Cheung VG, Utz PJ, Kobilka BK, Yamada T, Lefkowitz R. Saving the endangered physicianscientist - a plan for accelerating medical breakthroughs. N Engl J Med 2019;381(5):399-402. https://doi. org/10.1056/NETMp1904482

8. Booi M, Vincent L, Liccardo S. Counting on demographic equity to transform institutional cultures at historically white South African universities? High Educ Res Dev 2017;36(3):498-510. https://doi. historically white South African uniter
org/10.1080/07294360.2017.1289155

9. Karodia AM, Shaikh A, Soni D. The South African universities post-merger mess: Problems and

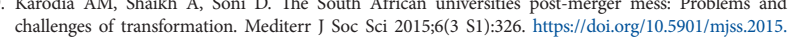
v6n3slp326
10. Tariq H, Thomson D, Kahn D. 10-year review of Africa’s first student surgical society - UCT Surgical Society. S Afr J Surg 2017;5(2):6-8.

11. DeLuca GC, Ovseiko PV, Buchan AM. Personalized medical education: Reappraising clinicianscientist training. Sci Transl Med 2016;8(321):321. https://doi.org/10.1126/scitranslmed.aad0689
s.

12. Bovijn J, Jacobs A, Boswell M, du Bruyn E, Bovijn L, Berkowitz N. Junior medical researchers: A neglected community with great academic potential. S Afr Med J 2015;105(11):884-885. https://doi. org/10.7196/samj.2015.v105i11.10179

Accepted 13 August 2019 